\title{
LLS use and Proficiency: Assamese ESL Learner's Context
}

\author{
Dr. Atonu Kakoty \\ Associate Professor \\ Department of English \\ DDR College \\ Chabua, Assam, India \\ kakotyatonu@gmail.com
}

\begin{abstract}
This paper studies the relationship of Language Learning Strategies (LLS) use and proficiency. Four hundred and fifty undergraduate Assamese ESL learners from three colleges of Dibrugarh University, Assam participated in the study. The aim of the paper is to investigate the relationship of Assamese ESL Learner's use of LLS and reading and writing proficiency in English. A Strategy Inventory for Language Learning (SILL) based questionnaire is used to identify learner's use of LLS and a reading and writing activity questionnaire is used to measure learner's proficiency. The participants answered the instruments at the beginning of the experiment, followed by LLS instruction for four weeks and a post-test on the same questionnaires. The Pearson's correlation analysis revealed significant positive correlation between the use of all the six types of LLS categories and learner's proficiency in reading and writing, both in the pre and post-test context. The study recommends that LLS instruction should be integrated in the undergraduate ESL classrooms to increase learner's proficiency in English.
\end{abstract}


Keywords: Language Learning Strategies, LLS and Proficiency, Assamese ESL Learners, ELT

Introduction

In Assam, English is learnt as a second or associate language in the educational institutions from primary level of education. In the recent years, with the liberalisation of Indian economy in the last part of the $20^{\text {th }}$ century, the English language requirement received additional momentum. Adequate proficiency in English became unavoidable requirement and part and parcel of today's education. Motivation for learning the language is quite favourable in the society. However, despite having a strong positive requirement for learning English, a large section of learners exhibits proficiency below expected level even at the undergraduate levels.

It has been a common observation that some students are more successful in learning a new language than others. Disparity in learning a language has been a subject of research. Modern researches in the field of language learning have been providing insights into how the learners of a language approach the learning of a language. It has been pointed out that learning a language is a complex cognitive process. It is a type of problem solving for which learners use different LLS. Language learning strategies are specific methods or techniques used by individual learners to facilitate the comprehension, retention, retrieval and application of information for language learning and acquisition (Oxford, 1990). In a nutshell, LLS are 'operations employed by the learner to aid the acquisition, storage, retrieval, and use of information...; specific actions taken by the learners to make learning easier, faster, more enjoyable, more self-directed, more effective, and more transferable to new situations' (Oxford, 1990:8). Therefore LLS are good indicators of how learners approach tasks or problems encountered during the process of language learning. An 
important area of investigation in the field of LLS research is to understand the relationship of LLS with proficiency. A considerable number of studies have investigated the relationship such as Lai (2009), Salahshour, Sharifi\&Salahshour (2013)Hasan\&Paramasivam (2016), Alfian (2018) etc.

Lai (2009) investigated language learning strategies used by 418 EFL learners in Taiwan and looked for relationships between learning strategy use and the patterns of strategy use based on language proficiency. The results indicated that proficiency level has a significant effect on strategy choice and use. In other words, more proficient learners used more learning strategies.

Salahshour, Sharifi\&Salahshour (2013) conducted a study on Iranian high school learners to explore the relationship between choice of learning strategies and English proficiency. The results indicated that proficient learners use significantly more strategy.

Hasan\&Paramasivam (2016) conducted a study to investigate the relationship between the use of language learning strategies and English proficiency of 124 Kurdish preuniversity students. The researcher used Oxford's (1990) SILL, individual background questionnaire and a version of English Sunrise Test for the investigation. The results revealed that in addition to proficiency, learner's learning level also influence LLS use. More advanced level learners use greater number of strategies.

Alfian (2018) conducted a study to explore the relation between language proficiency level and language learning strategy choice of EFL learners at an Islamic university in Indonesia. A total of 284 Indonesian university students classified as high, medium, and low based on their proficiency levels completed the SILL questionnaires. The findings indicated a linear relationship between proficiency level and strategy use; the higher the proficiency level, the higher the number of strategies employed. 
Hypothesis and Research Questions

In the context of the above discussion, present study tries to investigate the relationship of Assamese ESL learner's reading and writing proficiency with their use of LLS. Following hypothesis and research questions guided the present study.

$\mathrm{H}_{0}$ : There is no significant relationship between Assamese ESL learners' reading and writing proficiency in English and the use of Language Learning Strategies (LLS).

Research Questions:

1. Is there any relationship between Assamese ESL learners' use of LLS and their performance in reading and writing proficiency test before LLS instruction?

2. Is there any relationship between Assamese ESL learners' use of LLS and their performance in reading and writing proficiency test after LLS instruction?

Methodology

A total of 450 undergraduate Assamese ESL learners from three colleges of Dibrugarh University, Assam, participated in the study. The age of the participants was 19 to 20 years at the time of the experiment. They had 10 to 12 years of English learning experience. The study used two instruments:

a. A SILL (Oxford, 1990) based questionnaire to measure learner's use of LLS.

b. A reading and writing activity questionnaire to measure learner's proficiency in reading and writing in English.

The SILL based questionnaire was developed from Oxford's (1990) Strategy Inventory for Language Learning (SILL, Version 7.0). Oxford's SILL was intended for the students of English as a second or foreign language. It contained fifty multiple choice items, each representing one strategy. In the present study, some modifications were made to the SILL questionnaire. This was necessary because in the original version there were certain strategy 
items which were either unusual for the Assamese ESL learners of undergraduate level or specifically unrelated to reading and writing skill. Therefore, some strategy items were removed, modified or added for the purposes of the present study. The final version of the questionnaire contained 42 strategy items.

The reading and writing activity questionnaire was an instrument designed to test the participants' reading and writing proficiency in English. The questionnaire contained a total of 20 multiple choice comprehension questions, 5 each from four passages, to test the reading comprehension ability of learners. Two passages were selected from previous undergraduate level question papers of Dibrugarh University and the rest two passages were based on TOEFL (2005)

Learners' proficiency in writing skill was assessed with the help of two summary writing activities and an essay writing activity incorporated in the reading and writing activity questionnaire. The learners were asked to write summaries of two passages given for the reading comprehension task. Topics for the essay writing activity were selected from TOEFL (2005). These included topics of general interest of learners which help in the assessment of learners' ability for descriptive and argumentative writing. There were four options for the essay writing task. The questionnaire contained space in it for writing the summaries and the essay.

Results and Findings

Results for the research question 1:

1. Is there any relationship between Assamese ESL learners' use of LLS and their performance in reading and writing proficiency test before LLS instruction? 
Pearson's correlation test was carried out to see if there was any relationship between Assamese ESL learners' use of LLS and their performance in reading and writing proficiency test before LLS instruction.

Table 1: Proficiency Test Score and LLS Use in Pre-test

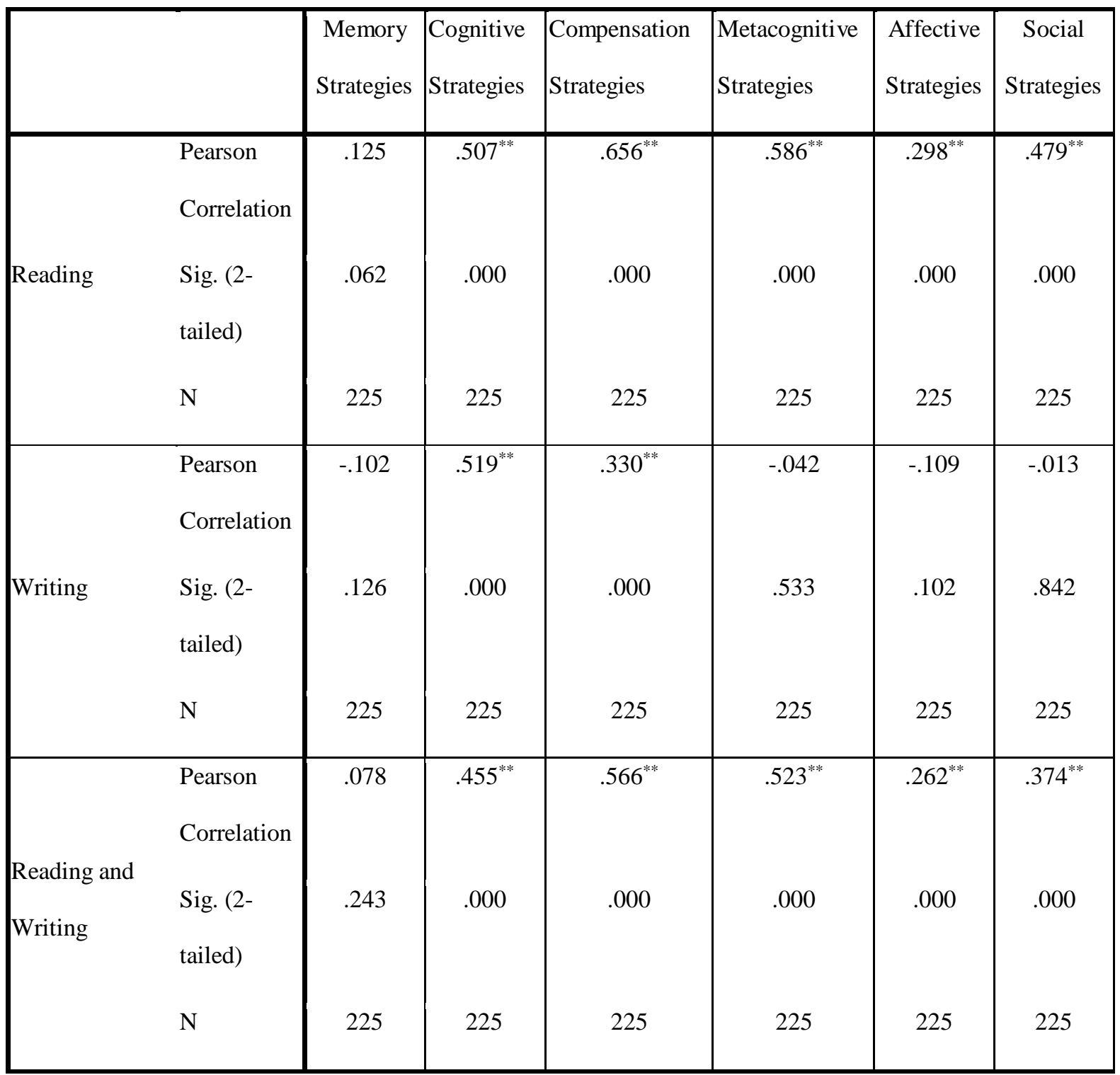

*. Correlation is significant at the 0.05 level (2-tailed).

**. Correlation is significant at the 0.01 level (2-tailed).

Table 1 shows that there is significant positive correlation $(\mathrm{p}<.01)$ of experimental group's reading and writing proficiency and the use of all the LLS categories except memory strategies of SILL. Therefore, it can be concluded that except memory strategies, the use of 
all the LLS categories have significant positive impact on the Assamese ESL learners' reading and writing performance before LLS instruction.

2. Is there any relationship between Assamese ESL learners' use of LLS and their performance in reading and writing proficiency test after LLS instruction?

Table 2: Proficiency Test Score and LLS Use in Post-test

\begin{tabular}{|c|c|c|c|c|c|c|c|}
\hline & & $\begin{array}{l}\text { Memory } \\
\text { Strategies }\end{array}$ & \begin{tabular}{|l|} 
Cognitive \\
Strategies
\end{tabular} & $\begin{array}{c}\text { Compensation } \\
\text { Strategies }\end{array}$ & $\begin{array}{c}\text { Metacognitive } \\
\text { Strategies }\end{array}$ & $\begin{array}{l}\text { Affective } \\
\text { Strategies }\end{array}$ & \begin{tabular}{|c} 
Social \\
Strategies
\end{tabular} \\
\hline Reading & \begin{tabular}{|l} 
Pearson \\
Correlation \\
Sig. (2- \\
tailed) \\
$\mathrm{N}$
\end{tabular} & $\begin{array}{l}.768^{* * *} \\
.000 \\
\\
225\end{array}$ & $\begin{array}{l}.736^{* *} \\
.000 \\
225\end{array}$ & $\begin{array}{l}.768^{* *} \\
.000 \\
\\
225\end{array}$ & $\begin{array}{l}.384^{* * *} \\
.000 \\
225\end{array}$ & $\begin{array}{l}.585^{* * *} \\
.000 \\
.25\end{array}$ & $\begin{array}{l}.497^{* *} \\
.000 \\
\\
225\end{array}$ \\
\hline Writing & \begin{tabular}{|l} 
Pearson \\
Correlation \\
Sig. (2- \\
tailed) \\
$\mathrm{N}$
\end{tabular} & $\begin{array}{c}.585^{* *} \\
.000\end{array}$ & $\begin{array}{l}.656^{* *} \\
.000 \\
\\
225\end{array}$ & $\begin{array}{l}.734^{* *} \\
.000 \\
225\end{array}$ & $\begin{array}{l}.374^{* *} \\
.000 \\
\\
225\end{array}$ & $\begin{array}{l}.599^{* *} \\
.000 \\
\\
225\end{array}$ & $\begin{array}{l}.623^{* *} \\
.000 \\
\\
225\end{array}$ \\
\hline $\begin{array}{l}\text { Reading } \\
\text { and } \\
\text { Writing }\end{array}$ & \begin{tabular}{|l} 
Pearson \\
Correlation \\
Sig. (2- \\
tailed) \\
$\mathrm{N}$
\end{tabular} & $\begin{array}{l}.000 \\
.225\end{array}$ & $\begin{array}{l}.000 \\
.225\end{array}$ & $\begin{array}{r}.000 \\
.225\end{array}$ & $\begin{array}{l}.000 \\
.225\end{array}$ & $\begin{array}{l}.632^{* *} \\
.000 \\
\\
225\end{array}$ & $\begin{array}{l}.554^{* *} \\
.000 \\
\\
225\end{array}$ \\
\hline
\end{tabular}

*. Correlation is significant at the 0.05 level (2-tailed).

**. Correlation is significant at the 0.01 level (2-tailed).

The result of the correlation analysis in Table 2 reveals that after LLS instruction there is significant correlation between the reading and writing proficiency test and the use of 
all the LLS categories. In other words, the use of all the six LLS categories has a significant positive impact on the reading and writing proficiency of the Assamese ESL learners after LLS instruction. The results of the correlation analysis of both before and after the LLS instruction provide enough evidence to reject the null hypothesis because the significant correlation was found both in the pre-test and post-test contexts.

Discussion

A SILL based questionnaire was used to measure learner's use of LLS and a reading and writing activity questionnaire was used to measure learner's proficiency in reading and writing in English. The findings indicated strong relationship of LLS and proficiency both in pre and post-test contexts. More proficient learner uses more LLS. In other words, higher use of LLS is associated with higher proficiency level of undergraduate Assamese ESL learners. The finding supports the finding of Lai (2009), Salahshour, Sharifi\&Salahshour (2013), Hasan\&Paramasivam (2016), Alfian (2018) etc.

\section{Conclusion}

The present study was conducted to investigate the relationship of LLS with proficiency of Assamese ESL learners. The findings revealed significantly strong relationship of LLS use with proficiency. It can therefore be recommended that LLS instruction should be incorporated in the ESL teaching learning situation in the undergraduate level in order to increase Assamese ESL learner's proficiency in English. Moreover, further studies of similar type should be conducted by inclusion of greater number subjects and variety of settings. 


\section{References}

Alfian, Alfian. (2018). Proficiency level and language learning strategy choice of Islamic university learners in Indonesia. TEFLIN Journal, 29(1). 1-18. Retrieved on 12/10/2019 from http://journal.teflin.org/index.php/journal/article/view/579/290

Hasan, Hemin \& Paramasivam, Shamala. (2016). Language Learning Strategies Across Proficiency Levels Among EFL Pre-University Students. Journal of Applied Linguistics and Language Research. 3. 135-148. Retrieved on 19/12/2018 from: https://www.researchgate.net/publication/304999355_Language_Learning_Strategies _Across_Proficiency_Levels_Among_EFL_PreUniversity_Students/link/577e800c08aed807ae7b1c04/download

Lai, Ying-Chung. (2009). Language earning strategy use and English proficiency of university freshmen in Taiwan. TESOL Quarterly, 43(2). 255-280. Retrieved on 22/11/2017 from: https://doi.org/10.1002/j.1545-7249.2009.tb00167.x

Oxford, R L. (1990). Language learning strategies: What every teacher should know. New York: Newbury House.

Salahshour,Farzad.,Sharifi, Mahnaz. \&Salahshour, Neda. (2013). The relationship between language learning strategy use, language proficiency level and learner gender. Procedia - Social and Behavioral Sciences, 70. 634-643. Retrieved on 12/07/2019 from:http://www.sciencedirect.com/science/article/pii/S1877042813001043

TOEFL. (2005). Test of English as a Foreign Language (TOEFL) test and score manual. Princeton, NJ: Educational Testing Service. 